\title{
A Linguagem do Respeito. A Experiência Brasileira e o Sentido da Cidadania nas Democracias Modernas*
}

Dominique Vidal

$\mathrm{E}$ ste texto objetiva mostrar que a análise da reivindicação de respeito, ponto central do discurso social e político do brasileiro pobre que mora nas cidades, permite destacar uma dimensão primordial do sentido da cidadania democrática nas sociedades modernas contemporâneas ${ }^{1}$. Os problemas de acesso à cidadania que as camadas populares enfrentam no Brasil podem lançar uma nova luz sobre certas formas da necessidade de reconhecimento manifestada nas sociedades do hemisfério norte, parecendo, assim, oportuno integrar a contribuição das pesquisas efetuadas nas sociedades do Sul aos debates contemporâneos sobre a modernidade.

Há de fato três maneiras principais de tratar a relação entre a teoria social e o conhecimento sociológico produzido a propósito das sociedades do Sul. A primeira aplica indiferentemente a todos os conjuntos sociais os conceitos e os paradigmas elaborados no estudo de algumas sociedades ocidentais, principalmente, Estados Unidos, Alemanha, França e Inglaterra, com eventuais incursões por Canadá, Itá-

\footnotetext{
* O autor agradece aos dois pareceristas anônimos de Dados por seus pertinentes comentários. [A tradução do original em francês "Le Langage du Respect. L'Expérience Brésilienne et le Sens de la Citoyenneté dans les Démocraties Modernes" é de Estela Abreu.]

DADOS - Revista de Ciências Sociais, Rio de Janeiro, Vol. 46, nํ2, 2003, pp. 265 a 287.
} 
lia e países nórdicos. Esta é a abordagem dominante, que leva, como se sabe, a um olhar etnocêntrico (ou, mais precisamente, centrado na visão norte-americano-européia) sobre as sociedades do Sul. Esquece que a teoria social foi concebida sobretudo a partir de uma reflexão sobre um número reduzido de sociedades ocidentais. A segunda maneira contrapõe-se à primeira; apóia-se na recusa do que se convencionou chamar de "idéias importadas" em nome de uma teoria local, que seria a única apta a explicar a realidade nacional. Ela é defendida pelos que consideram conveniente construir uma teoria social específica para compreender os países da modernidade periférica. O problema é que uma proposta com essas características impossibilita qualquer intercâmbio entre pesquisadores de sociedades nacionais diversas, uma vez que as isola em uma alteridade irredutível. O terceiro enfoque é, a meu ver, o único possível para se chegar a construir um espaço de debate que incorpore a diversidade das experiências nacionais. Ele pressupõe o reconhecimento, por um lado, de que todas as sociedades possuem interesse sociológico equivalente e, por outro, de que o saber sociológico produzido sobre o Sul é capaz de fornecer elementos para a compreensão dos fatos e processos observados no Norte. É neste sentido que gostaria de trazer aqui uma contribuição, mesmo que limitada.

Mostrarei, primeiro, como é fundamental o anseio por respeito e a denúncia da humilhação que se verifica nos meios populares urbanos no Brasil. Veremos como esse anseio por respeito oferece, por contraste, elementos para sustentar empiricamente a necessidade daquilo que o filósofo israelense Avishai Margalit (1999) denominou de "sociedade decente", entendida como uma sociedade cujas instituições não humilham seus membros. Examinarei, em seguida, a tensão entre hierarquia e igualdade que, no citadino brasileiro pobre, se expressa nesse anseio por respeito. Evocarei ainda algumas representações sociais e políticas das populações consideradas, o que me leva a inquirir sobre a relação entre vida moral e direito à proteção jurídica. Veremos, enfim, como a importância concedida à moralidade apresenta interesse para as discussões contemporâneas da sociologia do reconhecimento.

\section{RESPEITO E HUMILHAÇÃO}

A pregnância do raciocínio utilitarista nas ciências sociais decorre da incapacidade de seus pesquisadores para considerar algo além dos 
fatores econômicos. Embora neguem e apresentem complexos sistemas de interpretação, o tema que prevalece quando eles estudam questões de ordem política ${ }^{2}$ é o da desigualdade econômica. No Brasil, a reflexão sobre os obstáculos que os setores populares encontram ao pleno acesso à cidadania considera quase sempre como fator primordial a questão da distribuição de renda, indubitavelmente uma das mais desiguais do mundo. A pesquisa em ciências sociais, de modo geral, adota uma via correta quando considera as desigualdades sociais, sem dúvida, um entrave para o funcionamento da democracia e o exercício da cidadania. Por outro lado, a definição do interesse geral tornou-se impossível pela diversidade e, mais ainda, pela incomensurabilidade dos interesses particulares. A precariedade das condições de vida também não permite aos mais desfavorecidos uma participação ativa na vida política. É portanto inegável que a prática da cidadania democrática pressupõe, no Brasil, uma melhor distribuição da renda.

Mas o problema é que o enfoque quase exclusivo das ciências sociais sobre a questão das desigualdades econômicas tende a ocultar dimensões essenciais da cidadania democrática. Assim, em um país tão desigual como o Brasil, minhas pesquisas em Recife e no Rio de Janeiro sugerem que, para o citadino brasileiro pobre, o sentimento de pertencer à humanidade é muito mais importante que a redução da desigualdade social. Esse homem quase nunca condena a desigualdade social em si, mas sim o modo pelo qual, na vida cotidiana, os membros das camadas médias e superiores o fazem sentir-se socialmente inferior, seja nos espaços públicos ou no trabalho. O que ele deseja acima de tudo é ser reconhecido como membro legítimo da sociedade. Respeito é a palavra-chave de seu discurso sobre a injustiça social. Ponto central na avaliação da qualidade das relações sociais, a noção de respeito - e seu corolário, a denúncia da falta de respeito - permite-lhe apontar os que lhe negam o direito de pertencer plenamente à sociedade, pois raros são os brasileiros pobres que não tenham experimentado alguma vez a imensa distância que os separa dos membros das camadas superiores. Palavras cheias de subentendidos, um gesto de desconfiança ou um olhar esquivo bastam muitas vezes para que eles se sintam profundamente humilhados pela revelação de sua inferioridade social. Julgam-se também rebaixados à posição infame de delinqüentes ou mendigos quando passam por pessoas que, com medo de serem roubadas ou solicitadas a dar esmola, agarram precavida- 
mente suas bolsas e pacotes ou desviam rápido o olhar. O preconceito racial aparece às vezes de modo flagrante nesses afastamentos. As manifestações mais freqüentes, como a determinação do uso de elevadores de serviço nos prédios residenciais e a proibição de entrada em certos estabelecimentos de diversão, servem para lembrar o estigma que persegue o negro em uma sociedade que ainda se ressente das categorias escravagistas.

A exigência de respeito não é assunto novo. A julgar pela freqüência com que aparece nas discussões familiares, nas relações de trabalho ou nas brigas entre vizinhos, pode-se dizer que é uma das coisas mais bem distribuídas do mundo. É encontrada nas camadas populares de países com tradição democrática bem mais consolidada que a brasileira como, por exemplo, entre os operários ingleses, os jovens dos conjuntos populares periféricos, os negros dos guetos norte-americanos ou os porto-riquenhos do East Harlem (Bourgois, 1995). Mesmo assim, a noção de respeito não mereceu grande atenção dos cientistas sociais, ao passo que para os filósofos (Audard, 1993) é há muito objeto de uma reflexão específica. Talvez porque sociólogos e antropólogos não tenham tido interesse em um tema que pode parecer banal ou polissêmico. Ou talvez pela confusão freqüente que existe entre exigência de respeito e defesa da honra, tal como esta foi estudada nas sociedades mediterrâneas. Nessa perspectiva, podem ser citados com referência ao Brasil os trabalhos de Claudia Fonseca (1984) e de Marcos Alvito (1996). Embora eu concorde com muitas de suas análises, acho que não convém confundir essas duas noções em sociedades modernas e individualizadas nas quais, ao contrário do mundo mediterrâneo, a identidade já não é diretamente conferida pela estrutura social, mas se constrói quase sempre mediante um processo de afirmação do indivíduo com relação aos papéis institucionais ${ }^{3}$. Nos grupos rurais estudados no litoral do Mediterrâneo, a honra supõe como contrapartida uma conduta imperativamente compatível com um código de comportamento, sob pena de perda da identidade social. Por isso, ela tem um papel fundamental na regulação dos comportamentos e na construção da identidade pessoal.

Nas sociedades tradicionais pouco atingidas até há pouco tempo pela mudança social, a honra apóia-se principalmente no controle da sexualidade da mulher pelo homem e na importância da vingança. Ora, no Brasil urbano, o respeito não é ameaçado pelas investidas contra a pureza sexual da mulher. Os homens, por seu lado, não se sentem res- 
ponsáveis pela preservação da virgindade de suas irmãs e filhas, nem das outras mulheres do grupo familiar. Nas recomendações às adolescentes, as mulheres, em especial as mães, procuram evitar às jovens os inconvenientes da maternidade precoce, sobretudo o isolamento de quem, pobre, deve criar sozinha o filho. Os conflitos referentes à sexualidade nas camadas populares brasileiras parecem-me mais ligados aos temas da "reputação" e da "respeitabilidade", que, como mostram os trabalhos de Peter Wilson sobre o Caribe, não correspondem aos da honra e da vergonha, centrais na antropologia da honra que se elaborou a partir da observação das sociedades chamadas mediterrâneas (ver, p. ex., Wilson, 1969).

Enfim, se nos meios populares brasileiros há referência constante a um código de comportamento, há também distância entre o discurso sobre as prescrições normativas que cada um deve observar e a prática efetiva dessas prescrições. Ou seja, o respeito à brasileira não possui o caráter imperativo que aparece no sentimento de honra entre as tribos da Cabília argelina, os camponeses andaluzes ou os aldeões da Albânia.

Isso leva a pensar que a linguagem do respeito possui uma dimensão específica nas camadas populares das sociedades modernas, tendo em vista que associa intimamente a importância conferida ao reconhecimento da humanidade com o sentido dado à idéia de cidadania.

A reivindicação de respeito formulada pelo citadino brasileiro pobre também nos interessa na medida em que destaca um aspecto central da cidadania democrática moderna. O vínculo entre a necessidade de respeito e a denúncia da humilhação social é de fato um traço essencial das sociedades modernas que não tem recebido, a meu ver, a devida atenção nas pesquisas contemporâneas sobre democracia. Ao contrário das sociedades tradicionais em que hierarquias rígidas determinavam o status de cada um dos diferentes grupos sociais, nas sociedades modernas o sentimento de inferioridade é insuportável. Nestas, cada indivíduo reclama o direito de ser tratado como igual ou, ao menos, de não ser definitivamente classificado em uma posição de inferioridade. Na verdade, é o fato de ver lembrada a sua condição de inferior que provoca o sentimento de humilhação ${ }^{4}$.

O trabalho de Avishai Margalit apresenta uma perspectiva para interpretar a preocupação com o respeito e a sensibilidade à humilhação 
do citadino brasileiro pobre ${ }^{5}$. De acordo com este autor, é preciso levar em conta os problemas suscitados pela experiência da humilhação para construir não apenas uma sociedade justa, mas uma sociedade que não humilhe seus membros mais fracos. Seus argumentos vão bem além da idéia de sociedade justa fundada no equilíbrio entre liberdade e igualdade. Se não cabe aqui discutir a crítica que Margalit faz à teoria da justiça proposta por John Rawls, nem as dificuldades que a transposição empírica de sua filosofia social cria para o sociólogo, digamos brevemente que ele considera que é mais fácil construir uma "sociedade decente" do que uma sociedade justa. Segundo Margalit, sociedade decente é aquela em que ninguém pode ser humilhado pelas instituições. Sob vários aspectos, reconhece-se nesse conceito de humilhação aquilo que o habitante pobre da cidade considera humilhante. Em seu discurso sobre a injustiça social, esses indivíduos se referem constantemente à brutalidade policial, ao mau atendimento que recebem no serviço público e a atitudes condescendentes por parte de quem ocupa cargos importantes. As empregadas domésticas também se queixam dos patrões que dão ordens e as repreendem como se falassem com um cachorro e que lhes fornecem comida de má qualidade. Quando passam por esse sentimento de humilhação, os brasileiros pobres falam de "falta de respeito" e costumam dizer que são tratados não como seres humanos, e sim como animais. Isso faz pensar no conceito de humilhação de Margalit, que a define como "a recusa de formas específicas de vida pelas quais os seres humanos exprimem sua humanidade" (1999:15). Ora, é exatamente um sentimento desse tipo que a gente do povo experimenta quando se diz humilhada.

Há uma forte ligação entre o sentimento de ser desumanizado e o de não pertencer à sociedade. Certamente não é uma grande novidade. O direito a ser tratado como ser humano está no âmago dos direitos civis. Apesar disso, muitos problemas do acesso à cidadania nos países do Norte são decorrentes do fato de um número crescente de indivíduos se achar privado da proteção da lei, como é o caso dos imigrados clandestinos e dos sem domicílio fixo. Muitas pesquisas mostram o sentimento de humilhação que esses indivíduos em situação precária e sem proteção experimentam nas interações com as instituições dos países onde tentam estabelecer-se. Para eles, o motivo desse sentimento de humilhação está em não serem considerados como seres humanos. O mais difícil de suportar não são as más condições de habita- 
ção ou de trabalho, mas a diferença de tratamento por parte das instituições e repartições que não os vêem como vêem os outros membros do corpo social.

\section{O RESPEITO: ENTRE HIERARQUIA E IGUALDADE}

Minha abordagem da noção de respeito entre os citadinos brasileiros pobres não se baseia em um conceito de respeito tirado da tradição filosófica nem tenta propor uma definição de respeito fixa e precisa ${ }^{6}$. Considero, na linha dos antropólogos, a palavra respeito como uma categoria nativa sobre a qual é preciso compreender o significado. Logo, a partir da análise dessa palavra tal qual é utilizada, como categoria comum da linguagem corrente do citadino brasileiro pobre, procuro mostrar quanto a diversidade dos usos desse termo revela a ambivalência que domina esses setores sociais no Brasil contemporâneo. Nessa perspectiva, cabe refletir sobre o que pode significar o emprego da categoria respeito em frases como: "Hoje em dia, não tem mais respeito"; "Antigamente, o governo respeitava o pobre"; "A pessoa que quer o respeito tem que respeitar o outro"; "Minha patroa não me paga bem, mas ela me respeita muito"; "Em casa de família, cada pessoa tem seu lugar, mas não pode faltar o respeito".

Seria possível sustentar, de modo geral, que esse pedido de respeito corresponde à necessidade do indivíduo de ver reconhecido o lugar que ele julga merecer em determinada ordem social, assim como às prerrogativas que parecem adequadas ao papel a partir do qual se reivindica o respeito. A preocupação de ver sua própria apresentação de si confirmada por outrem revela-se, sem dúvida, em todos os pedidos de respeito. Mas em vez de propor uma noção reificada do respeito, irei me deter nas tensões que atravessam essa reivindicação, pois a precariedade das condições de vida nos meios populares favorece a persistência de uma representação holística da ordem social à custa da plena aceitação do ideal de igualdade da democracia moderna. A demanda por respeito expressa de fato não só uma preferência pelas antigas formas de relações hierárquicas entre dominantes e dominados, mas também um pedido de igualdade que é complexo. Embora as ligações da noção de respeito com o princípio hierárquico e a idéia de igualdade apresentem um aspecto movediço, segundo os contextos de interação, é possível situar analiticamente três configurações distintas dentro da subjetividade dos indivíduos. 
A primeira remete a um significado do respeito que expressa a busca por relações hierárquicas no âmbito de uma representação orgânica da sociedade. Aqui não cabe a idéia de igualdade. Para os indivíduos em situação de inferioridade, o sentimento de pertencer plenamente a uma sociedade depende da proteção dos dominantes. O comportamento paternalista do empregador para com o empregado é a melhor ilustração dessa expectativa. Tipo de relação herdado do mundo rural, a vassalagem ao patrão como contrapartida a um lugar garantido permite ao subalterno construir sua identidade pessoal em um universo no qual a ameaça de rejeição social nunca o deixa. Nessa configuração, a relação paternalista, forma de dominação e relação de dependência pessoal, chega a ser preferida à ausência de vínculo com os dominantes.

A segunda configuração apóia-se na afirmação da humanidade comum de todos os membros do corpo social, assertiva que procede da rejeição de tudo o que evoca a condição de escravo. Enquanto o arranjo anterior é impermeável à idéia de uma forma de igualdade entre dominantes e dominados, no agora em questão aparece, em filigrana, uma idéia de igualdade cuja tela de fundo é o abalo de antigas hierarquias em uma sociedade conquistada pelo imaginário igualitário da democracia. Tal configuração pressupõe o reconhecimento de uma certa forma de igualdade entre os indivíduos sem que com isto seja abandonada uma visão hierárquica do social. Porque, que não haja engano - e é o que distingue esta segunda configuração da terceira-, a idéia de igualdade no sentido moderno do termo ainda não se firmou definitivamente. O pedido de igualdade que ali se expressa é mais parecido com a idéia de "igualdade civil", tal como foi historicamente formulada na linha do princípio cristão de igual dignidade dos homens diante de Deus. Nessa configuração, a reivindicação de respeito apóia-se quase sempre no tema cristão da dignidade da pessoa humana, que aliás organiza muitas denúncias do destino injusto que cabe aos mais desfavorecidos. Com a instauração de um regime democrático, a ambivalência do apelo ao respeito atinge talvez seu ponto mais elevado. Esse pedido de igualdade tanto pode sustentar a afirmação da primazia do indivíduo sobre o todo social, afirmação esta que está no fundamento da visão moderna de democracia, como traduzir o vigor de uma representação orgânica e hierárquica da sociedade.

Em uma terceira configuração, a exigência de respeito traduz a recusa de uma sociedade hierárquica na qual os lugares estão demarcados 
de antemão. Não se trata de humanidade comum dos dominantes e dominados, e sim de "semelhança dos homens" no sentido que Tocqueville deu ao termo ${ }^{7}$. O respeito não se manifesta a partir de posições precisas, mas supõe que a identidade absoluta dos indivíduos seja reconhecida, o que o autor de A Democracia na América chama de igualdade de condições, isto é, o traço estrutural das sociedades democráticas em que o trabalho permanente de redução da alteridade entre os homens deve progressivamente apagar as distinções da natureza. A esperança de ascensão social confirma esse anseio de mobilidade por parte de uma sociedade em que nenhuma diferença essencial impede o acesso a uma posição desejada. Algumas identificações com modelos culturais da sociedade global - por exemplo, o desejo de fazer um curso superior e de exercer uma profissão valorizada socialmente, o de estar na moda, o de freqüentar os shopping centers ou a penetração da world music nos meios populares - atestam igualmente a busca de uma uniformidade simbólica, marcando a semelhança de todos acima das desigualdades econômicas. Quando os indivíduos se consideram assim membros de uma sociedade que permite a mobilidade social, desligados de todos os vínculos primeiros não escolhidos e radicalmente iguais por natureza, é uma reivindicação de igualdade no sentido moderno do termo que se enuncia, e essa forma de igualdade é que está no princípio da idéia de cidadania política da democracia.

Nenhuma dessas três configurações se firma a ponto de apagar as outras. Sua co-presença é a originalidade da noção de respeito entre indivíduos confrontados com a mudança social e com a transformação política em um período de incerteza. No âmago das relações fundadas tanto em um princípio hierárquico ("rico" /"pobre", empregador/empregado, patroa/empregada, marido/mulher, pai/filho) quanto na igualdade (entre parentes colaterais, amigos ou vizinhos), a referência ao respeito constitui, de acordo com os contextos, um princípio de gestão da desigualdade ou a afirmação de formas diversas de igualdade entre os indivíduos. $\mathrm{O}$ apelo ao respeito é um testemunho simultâneo do peso da história, manifestado no vigor das formas de hierarquização social existentes na escravatura, bem como da novidade do momento presente, revelada no reconhecimento do indivíduo independentemente de suas origens. Central na avaliação de muitas interações, a idéia de respeito expressa o que constitui um vínculo social para indivíduos em situação de inferioridade. Tal noção 
lhes permite denunciar aqueles que, por uma atitude ou palavra, parecem recusar-lhes o direito de pertencer plenamente à sociedade ou não fazem distinção entre os que têm um lugar na ordem social, mesmo que em posição subalterna, e os que dela são rejeitados pelo comportamento infrator de regras que asseguram a preservação do vínculo social.

Minha análise da ligação complexa entre a noção de respeito e as idéias de hierarquia e de igualdade difere consideravelmente da efetuada pelo antropólogo Roberto DaMatta. Em trabalhos de grande interesse, ele sugere que, no Brasil, um código hierárquico e um código igualitário agem simultaneamente em inúmeras práticas (DaMatta, 1979; 1985; 1993). Se DaMatta considera a coexistência desses dois códigos como princípio central para explicar a sociedade brasileira, minha interpretação insiste, ao contrário, na indeterminação da noção de respeito no momento da proclamação dos ideais igualitários e individualistas da democracia moderna em um contexto de desorganização e de desestruturação das antigas formas de vínculo social. À abordagem nitidamente anistórica de DaMatta, preferi sublinhar, pela consideração dos efeitos dessas mudanças sobre as representações sociais e políticas da população estudada, a fragilidade das configurações em que se encontram o princípio hierárquico e a idéia de igualdade ${ }^{8}$. É sobretudo por isso que irei apresentar diferentes formas de igualdade.

É isso que nos leva a um distanciamento da análise de DaMatta sobre as conseqüências políticas da não-separação entre espaço público e privado. No prolongamento de sua oposição entre o mundo da casa e o da rua, o autor explica a difícil realização da cidadania democrática no Brasil pela presença da "ética da casa" no espaço público'. Porque o Brasil não passou por essa revolução igualitária de que fala Tocqueville em A Democracia na América, a pregnância das relações pessoais fundadas na vinculação a uma mesma família, a lealdade e a amizade impediriam a formação de relações que supõem o reconhecimento da igualdade de todos os membros do corpo social. Segundo DaMatta, é por esse motivo que, em uma sociedade que proclama os valores democráticos, um princípio hierárquico rege as relações entre "superiores" e "inferiores" pela troca recíproca mas desigual da proteção contra a vassalagem. Mais uma vez, a abordagem anistórica do autor o impede de perceber o desenvolvimento, certamente lento e contraditório, do imaginário das sociedades democráticas igualitárias, o que 
vem confirmar os diferentes usos da noção de respeito ${ }^{10}$. Pois, ao contrário do que ele afirma, tudo o que representa o espaço público não é sistematicamente visto como perigoso pelos membros das camadas populares. Esses indivíduos não se sentem necessariamente em uma situação de despojamento e vulnerabilidade quando se encontram fora da proteção que lhes seria garantida pela inserção no mundo da casa. Como mostram inúmeras pesquisas empíricas, os jovens e as mulheres gostam muito de deixar a pretensa segurança do espaço doméstico (Vaitsman, 1997; Vidal, 2000b). A rua, a praia, os espaços comerciais ou o mundo do trabalho são para eles lugares onde também se conquista a autonomia e se exprime a individualidade. Eis por que gostam muitas vezes de freqüentar os espaços públicos, saindo do quadro doméstico que tanto constrange quanto protege.

\section{VIDA MORAL E DIREITO À PROTEÇÃO JURÍDICA}

Seja qual for a diversidade de suas trajetórias e de seus níveis de renda e de instrução, os moradores de Brasília Teimosa e as empregadas domésticas que entrevistei em Recife e no Rio de Janeiro concordam em um ponto: o direito de ser tratado como gente só pode ser pleiteado por quem age dentro de um conjunto de obrigações - pensadas como obrigações morais - que definem a humanidade. As palavras obrigação e dever perpassam seus discursos, desde que se trate de julgar o comportamento de um indivíduo. E há também a idéia de que compete a cada um se comportar de acordo com essas obrigações morais para ser considerado como ser humano e ter a proteção do direito. Por isso, a grande maioria das duas populações entrevistadas avalia que nada justifica o roubo do bem alheio; que o papel do pai é prover, pelo trabalho, às necessidades da família; que a função da mulher é cuidar da educação dos filhos e da vida do lar; que os filhos, por sua vez, devem obedecer aos pais; que os vizinhos e amigos devem ser solidários entre si diante das dificuldades que a vida apresenta; e que, no campo das relações profissionais, o empregado deve aceitar as ordens do patrão se este o tratar com "o devido respeito", não o insultar e o ajudar quando ele estiver em dificuldades.

Mas convém que uma coisa fique clara: não se pode deduzir a realidade social com base nesse discurso estereotipado, quase sempre distante da prática real, pois o estudo do cotidiano revela uma distância considerável entre essas normas repetidas incessantemente e a observação dos fatos. Os conflitos familiares são muito freqüentes, a soli- 
dariedade nem sempre funciona e muitas empregadas domésticas utilizam estratégias individuais bem afastadas da obediência, que elas reconhecem como um atributo de uma relação de trabalho de qualidade.

Logo, o interesse desse discurso está no fato de ele exprimir o ideal de uma sociedade harmoniosa e a necessidade de civilidade na vida social. Pois dessas representações se extrai a idéia de que uma boa sociedade é aquela em que cada um trata o outro com respeito, e que, além disso, quem dá provas de seu respeito goza da proteção jurídica do Estado, isto é, usufrui da garantia de sua segurança individual, do benefício da previdência social e do direito ao trabalho. Com base nessas afirmações sobre as obrigações morais que devem reger os supostos coletivos formados pelos parentes, vizinhos e amigos, pelos empregadores e empregados, seria cabível pensar que eles vivem de acordo com o modelo da Gemeinschaft, segundo o sentido dado a essa categoria por Ferdinand Tönnies (1977:56), isto é, uma "comunidade de sangue, de vinculação, de espírito" que se baseia no "parentesco, vizinhança, amizade". Quando seus membros afirmam que cabe a cada um "cumprir seus deveres", que "é a obrigação [de alguém] fazer determinada coisa", que "ele pode" ou "não pode" fazer isto ou aquilo, ou que fulano "está errado" ou "está certo", eles fazem referência a regras que se impõem a cada um. Tal como são enunciados, esses diferentes códigos de comportamento parecem completar-se e ter a força de governar o conjunto das relações possíveis. $O$ vínculo social parece provir da subordinação dos indivíduos às regras necessárias ao funcionamento perene de uma totalidade orgânica preexistente, e não de um contrato que fundamente o coletivo. Quando essas regras são evocadas, o sistema jurídico só é mencionado se ele concerne a essas obrigações definidas quanto ao social e se parece proveniente de uma lei natural.

Pode alguém pensar que não há nada de especificamente brasileiro nessas representações sociais. Muitas teorias da cidadania democrática consideram que o "bom cidadão" é o indivíduo que age de acordo com o sistema normativo dominante na sociedade ${ }^{11}$. O que chama a atenção no caso brasileiro é a ausência de qualquer menção à idéia de participação política nas representações da inclusão social. De fato, o citadino brasileiro pobre quase nunca fala do voto ou de outra forma de participação política quando se refere a seus "direitos"; quando fala deles, é em alusão quase exclusiva ao direito do trabalho e ao di- 
reito de ser tratado como ser humano (Caldeira, 1984). E pede a garantia do benefício desses direitos em nome de sua qualidade de ser humano ou, como se costuma dizer, "de gente", isto é, pede para ser tratado como ser humano porque se comporta de acordo com um conceito do que deveria ser, segundo ele, a humanidade.

Há uma conseqüência evidente desse conceito popular na associação entre obrigações morais e direitos: é a negação da proteção dos direitos humanos para quem é suspeito de crime. Para o citadino brasileiro pobre, quem infringe a lei não merece ser tratado como ser humano, o que leva, sobretudo, à justificação da tortura ou de assassinato de delinqüentes cometidos pela própria polícia. Essa ausência de identificação ao ideal dos direitos humanos foi muitas vezes apontada como um obstáculo à consolidação da democracia no Brasil, e não há dúvida de que é um sério limite para aprofundar a cidadania democrática.

Mas, ao mesmo tempo, a íntima ligação entre civilidade e cidadania lembra que esta última supõe um profundo sentido do bem comum e do compromisso entre os cidadãos (Thompson, 1970). Como mostram muitos estudos sobre o enfraquecimento da cidadania nos países do Norte, o declínio da civilidade nas relações sociais desgastou a idéia política de uma sociedade democrática com base em indivíduos livres protegidos por uma mesma lei (Banfield, 1992; Roché, 1998; Anderson, 1999). Parece-me, sob esse aspecto, que a linguagem do respeito dos brasileiros pobres incita a prestar mais atenção nos países de tradição democrática mais consolidada. Se for verdade que o aumento das desigualdades econômicas, o declínio do Estado-Providência e o enfraquecimento da soberania nacional estão fazendo com que as sociedades do Norte se assemelhem cada vez mais às do Sul, também é verdade que elas estão mais parecidas na baixa de civilidade na vida social bem como nos problemas que isso acarreta para o funcionamento da democracia.

\section{A LINGUAGEM DO RESPEITO E A SOCIOLOGIA DO RECONHECIMENTO}

A importância das relações de reconhecimento na vida social e política originou nas últimas décadas um grande número de trabalhos (Honneth, 1995; Todorov, 1995; Taylor, 1997; 1998; Chaumont e Pourtois, 1999). Nesse sentido, o discurso que o citadino brasileiro pobre utiliza quando fala das obrigações parece trazer elementos para essa discussão. Sugere, em primeiro lugar, que a importância da moralida- 
de nesse discurso não se confunde com a falsa consciência, como pode sugerir a análise inspirada em um marxismo vulgar, nem que éa mera conseqüência da violência simbólica exercida pelos dominantes sobre os dominados, como é o caso da abordagem inspirada nas pesquisas de Pierre Bourdieu. Pelo contrário, e embora os valores citados pelos brasileiros desfavorecidos sejam quase sempre os da sociedade global, a referência à moralidade parece-me antes de tudo um recurso essencial para a construção identitária nos meios populares, mesmo que ela também reflita a interiorização das categorias das camadas superiores. Sob esse aspecto, a linguagem do respeito é uma resposta prática dada à dominação social. Essa resposta prática insiste na conformidade social dos que estão em situação de inferioridade, os quais, em nome dessa conformidade, reivindicam o reconhecimento de sua existência pelos dominantes e a melhora de suas condições de vida pelos governantes.

Em segundo lugar, a importância concedida à vida pautada por obrigações morais contribui consideravelmente para contrabalançar a habitual opinião pessimista quanto ao funcionamento da democracia no Brasil. Convém lembrar que o imaginário de integração social do período de transição democrática ainda não foi realizado e que a questão social, sob vários aspectos, até se agravou. Não se pode esquecer que as demandas dos setores populares se baseiam não apenas no fato de os seus membros pertencerem à humanidade ("A polícia trata a gente como cachorro"; "No hospital, o pobre não é atendido como gente"), mas também à nação ("O governo tem a obrigação de ajudar todos os brasileiros"), e que, nas representações do povo, o Estado é visto como a instituição que deve garantir-lhe os direitos ("É dever do governo dar os direitos").

A participação política dos setores populares não se realizou conforme haviam anunciado os teóricos dos movimentos sociais no início da transição para a democracia. O sindicalismo perdeu muita força desde o começo dos anos 80, e os resultados das eleições foram surpreendentes: vitória de certos grupos com formação progressista e de outros ligados ao antigo regime militar. Mas convém lembrar que, no Brasil, a idéia de participação não é vista como a base dos direitos. Isso porque, como mostrou José Murilo de Carvalho (2001), sob o regime autoritário de Getulio Vargas, os direitos sociais foram concedidos antes dos direitos políticos, o que originou o simbolismo sempre presente da inclusão social pelo reconhecimento da miséria do povo 
pelos governantes. A lembrança desse gesto vindo do alto explica amplamente a falta de referência à participação política no sentido dado ao fato de pertencer à sociedade.

Convém assim mesmo fazer a distinção entre o que procede do funcionamento das instituições e as mudanças mais gerais ocorridas nas relações sociais. Pois, sejam quais forem as insuficiências do poder público, a necessidade de reconhecimento do pobre brasileiro remete ao ideal de uma sociedade democrática na qual a posição social não é predeterminada e, portanto, todos os seres humanos têm o mesmo valor.

Aliás, essa importância conferida às obrigações morais oferece uma base empírica para os textos de Axel Honneth (1995) sobre o reconhecimento. Vê-se, de fato, como atitudes morais e normas estão ligadas a formas de reconhecimento intersubjetivo. Ora, Honneth mostra como a partir da base desse vínculo é que se garante mutuamente as condições intersubjetivas da formação de nossa identidade. Há, além disso, um outro ponto da abordagem de Honneth que ajuda a compreender o comportamento do brasileiro desfavorecido: a idéia de que a luta pelo reconhecimento se apóia principalmente em uma gramática moral dos conflitos sociais. Encontra-se, por exemplo, esse tipo de demanda na maioria dos movimentos reivindicatórios urbanos: quando pedem a implantação de programas sociais ou a criação de infra-estrutura, justificam sua ação em nome da dignidade e do respeito devido aos pobres.

Ademais, ao contrário das abordagens utilitaristas, Honneth destaca que, na maioria dos conflitos, o indivíduo não busca a satisfação de interesses materiais, mas o respeito como ser autônomo e individualizado. Os conflitos entre as empregadas domésticas e seus patrões são um exemplo dessa dinâmica. Muitas das que encontrei no sindicato dos trabalhadores domésticos do Rio de Janeiro afirmavam ter abandonado o emprego e entrado com uma ação na Justiça do Trabalho não pela remuneração insuficiente, mas porque haviam sido desprezadas ou humilhadas pelo patrão. As condutas que essas mulheres consideram, segundo seus próprios termos, "injustas" ou "humilhantes" têm o caráter de ofensas morais. Depois de ter passado por isso, já não conseguiam estabelecer uma relação positiva consigo mesmas e se sentiam prejudicadas em sua capacidade de agir. Tratava-se, porém, quase sempre de gestos ou palavras à primeira vista in- 
significantes: um olhar irônico, um gracejo ("Você é mais rica do que eu, na sua casa tem microondas"), uma alusão a quem não freqüentou a escola ("Você não pode entender, você não tem estudo"), uma reprimenda sem motivo ou a ordem para ficar na cozinha quando chegava visita. Mas, na maioria das vezes, era o que bastava para marcar a deterioração da relação de trabalho, pois a doméstica já não conseguia sentir-se respeitada em sua atividade e em sua dignidade.

Minha pesquisa sugere, entretanto, que o alargamento do acesso à Justiça do Trabalho desde a Constituição de 1988 está mudando profundamente as relações entre as domésticas e seus patrões. Pelo reconhecimento jurídico, elas conseguem introjetar o sentido do que Axel Honneth denomina "respeito de si". Segundo este autor, o reconhecimento jurídico é de fato a admissão das características universais dos seres humanos. A necessidade de reconhecimento, como escreve Emmanuel Renault na linha dos trabalhos de Axel Honneth,

“[...] não expressa apenas a exigência de um comportamento justo em relação a mim, isto é, um comportamento que leve em conta minha dignidade, meu valor universal como pessoa humana, responsável e sociável; expressa também a necessidade de ser reconhecido como o indivíduo específico que sou na vida corriqueira sob a aparência das diversas identidades que apresento na interação social" (2000:59).

Sob esse aspecto também se percebe quanto as mudanças no relacionamento entre empregadas domésticas e patrões - típico da sociedade brasileira - podem ajudar a compreender o que ocorre nas relações entre lei e identidade nas sociedades do Norte e do Sul. É sabido que nos países do Norte a falta de documentos de identidade priva os imigrantes clandestinos do sentido do respeito de si e, por esse motivo, a sua legalização lhes oferece a possibilidade de construir sua identidade pessoal diante da lei.

\section{CONCLUSÃO}

À guisa de conclusão, desejo primeiro sugerir que, a despeito das diferenças nacionais, os problemas de acesso à cidadania lembram que há um ponto essencial no sentido dado a esta nas sociedades modernas contemporâneas: o sentimento de pertencer plenamente à sociedade supõe que previamente tenham o sentimento de pertencer à humanidade. Essa necessidade de reconhecimento da humanidade se 
encontra nos três elementos do estatuto jurídico do cidadão: o civil, o político e o social. Os direitos civis apóiam-se amplamente no reconhecimento do direito a ser tratado como ser humano; os direitos políticos baseiam-se no reconhecimento da igualdade de cada membro da comunidade política; os direitos sociais fundamentam o reconhecimento da reivindicação de proteção social.

Os observadores e os militantes mostram-se às vezes surpresos com o aumento da abstenção ou com o fraco interesse dos cidadãos pela política. Isso é ainda mais chocante em um país como o Brasil, onde o recente restabelecimento do processo democrático despertou muita esperança. Nesse ponto, também é necessário distinguir dois níveis de análise: o acesso a um direito e o exercício do mesmo. Os trabalhos de Judith Shklar a respeito dos Estados Unidos e de Pierre Rosanvallon sobre a França mostraram quanto a luta pelo reconhecimento da vinculação social foi, sob o aspecto histórico, bem mais vigorosa que a participação política (Shklar, 1991; Rosanvallon, 1992). Nesses dois países, o direito de voto foi de fato considerado mais como um símbolo da plena vinculação social que um direito a participar do governo. O que constitui, afinal, a especificidade do Brasil é que a importância conferida à plena vinculação social parece desligada da idéia de participação política.

Em outra ordem de idéias, quero voltar rapidamente a um ponto mencionado no início deste artigo: o enfoque excessivo das ciências sociais sobre as desigualdades econômicas e a distribuição de renda. Embora sejam questões fundamentais, convém não esquecer que os problemas das sociedades democráticas não se reduzem à política econômica stricto sensu. Sentimentos sociais como respeito e humilhação, dos quais vimos a importância, remetem a outras dimensões da experiência democrática. Eles exprimem uma reivindicação de reconhecimento no cerne da reflexão contemporânea sobre a cidadania democrática moderna.

É verdade que esses sentimentos sociais não se encontram apenas no Brasil, mas em todas as sociedades modernas, mas tudo indica que as tensões que caracterizam a sociedade brasileira tornam ainda mais evidente essa exigência de reconhecimento social. É possível até que a análise dos problemas de acesso à cidadania no Brasil exija uma distinção entre as demandas de igualdade e as de respeito. Como bem mostrou Harry Frankfurt (1997), trata-se de duas ordens diferentes, e 
o enfoque excessivo sobre as desigualdades econômicas impede muitas vezes que se veja o que essas demandas de respeito significam, sendo elas essenciais para a construção da identidade pessoal e para o estabelecimento de uma relação positiva do indivíduo consigo mesmo. As reivindicações de respeito que encontrei em minhas pesquisas em Recife e no Rio de Janeiro mostram, aliás, que a gestão prática dos problemas provocados pela desigualdade social nas sociedades contemporâneas não passa necessariamente pela realização da igualdade econômica. E, como sugere Richard Sennett (2003) em seu último livro, o objetivo do respeito mútuo é provavelmente um dos principais desafios das sociedades desiguais e diferenciadas com que nos deparamos hoje.

Portanto, além das suas diferenças, as atuais sociedades do Norte e do Sul devem enfrentar igualmente o enfraquecimento da capacidade de ação do Estado nacional e a queda da identificação com objetivos comuns. A questão da cidadania nas sociedades contemporâneas é, por esse motivo, indissociável daquelas ligadas à coesão social e à complexidade das identificações sociais, sobretudo étnicas. Os problemas que hoje os países do Norte enfrentam são, de longa data, os do Brasil e de outras sociedades do Sul. É por isso também que os dois principais campos para a compreensão da cidadania nas sociedades modernas são, a meu ver, por um lado, o estudo das condições de uma cidadania efetiva nos grupos sociais muito diversificados e, por outro, a reflexão sobre sentimentos sociais tais como respeito, humilhação e desprezo, que ocupam manifestamente lugar crescente na vida social e política.

(Recebido para publicação em janeiro de 2003) (Versão definitiva em julho de 2003) 


\section{NOTAS}

1. Este artigo se baseia em material recolhido, entre 1992 e 2000, junto à população de Brasília Teimosa, favela urbanizada de Recife, bem como em uma pesquisa em curso sobre as empregadas domésticas e o sentido de justiça no Rio de Janeiro. Realizada entre 1992 e 1994, uma primeira série de pesquisas, com duração total de dezoito meses, tratou das relações sociais, das práticas políticas e do papel das associações de moradores na implantação da intervenção social e no funcionamento do sistema político municipal (Vidal, 1998; 2000a; 2000b). Efetuada durante duas estadas, em 1998 e 1999, uma segunda pesquisa dedicou-se aos modos de entrada na vida adulta (Vidal, no prelo). Nos dois casos, o essencial do material coletado parte de uma abordagem etnográfica do campo, baseada, entre outros, em quase seis meses (não consecutivos) de residência no local, em inúmeras observações da vida social e em entrevistas continuadas com várias dezenas de moradores. Iniciada em 2001, a pesquisa sobre as empregadas domésticas e o sentido de justiça apóia-se em histórias de vida narradas por atuais ou ex-domésticas, em entrevistas com patrões e com atores do campo jurídico (magistrados, advogados) e em uma etnografia do Sindicato dos Trabalhadores Domésticos do Rio de Janeiro e do Tribunal Regional do Trabalho.

2. É possível afirmar sem exagero que a sociologia francesa contemporânea se estruturou principalmente em torno da discussão, explícita ou implícita, do tema da desigualdade. O exemplo mais conhecido é provavelmente a discussão sobre a desigualdade de oportunidades na escola que opôs as análises de Pierre Bourdieu e Jean-Claude Passeron $(1964 ; 1970)$ às de Raymond Boudon (1973).

3. O antropólogo Frank Henderson Stewart (1994), em um livro de sucesso, questionou a idéia de "honra mediterrânea" ou de "cultura mediterrânea". A despeito de certas semelhanças entre as noções de honra encontradas nas diferentes sociedades que margeiam o Mediterrâneo, não lhe parece possível pensar conjuntamente grupos que se definem de modo mais profundo pelo cristianismo e pelo islã. Com base em uma pesquisa histórica, ele mostra que a honra da Europa do norte não difere muito da da Europa do sul e que, se as idéias européias sobre a honra mudaram consideravelmente no decorrer do tempo, tais mudanças não apresentam diferenças de um país para outro, com exceção de Montenegro e da Islândia. A partir de suas pesquisas com os beduínos, ele afirma que a honra em muitos desses grupos é bem diferente da existente na Europa, tanto do norte como do sul. Assim, o código que os beduínos devem seguir para preservar sua honra e o leque de ações que constituem uma ofensa à sua honra são bem diversos daqueles que constituem ofensa à honra na Europa; em ambos os casos, as diferenças não estão em detalhes, mas em questões de princípio.

4. Como historiador da Islândia medieval e com base nas contribuições da pesquisa em teoria política, antropologia, psicologia e sociologia, William Ian Miller desenvolve com acuidade esse tema em uma série de ensaios (ver Miller, 1993).

5. Para um debate sobre a idéia de "sociedade decente" em Margalit, ver Margalit (1999).

6. Para uma análise conceitual do respeito, ver Patrick Pharo (2001). 


\section{Dominique Vidal}

7. Para um comentário mais completo dessa idéia em Tocqueville, ver o texto de Marcel Gauchet (1980).

8. No âmbito de um questionamento sobre o aumento da exigência de respeito nas sociedades contemporâneas, Danilo Martuccelli (2002) mostra que isto decorre da ênfase das dimensões subjetivas nas trocas sociais e é revelador das tensões e justaposições entre "regimes de interação" definidos pela hierarquia, pela igualdade e pela diferença.

9. Em outra perspectiva, Jessé Souza (2000) também desenvolve uma crítica sobre a oposição entre a casa e a rua de Roberto DaMatta.

10. Em pesquisa sobre o significado da referência à amizade nas relações entre empregadas domésticas e suas patroas, Claudia Rezende (2001) destaca o aspecto estático e pouco atento ao contexto situacional e às diferenças de classe que aparece na oposição entre o mundo da rua e o mundo da casa proposta por Roberto DaMatta.

11. Cf. o livro de Charles E. Merrian (1931), que oferece a esse respeito uma ilustração completa. Há também observações nesse sentido em certos trabalhos comentados por Jean Leca (1986) e na pesquisa de Sophie Duchesne (1997) sobre o significado do status de cidadão na França contemporânea.

\section{REFERÊNCIAS BIBLIOGRÁFICAS}

ALVITO, Marcos. (1996), “A Honra do Acari”, in G. Velho e M. Alvito (eds.), Cidadania e Violência. Rio de Janeiro, Editora UFRJ/Editora FGV, pp. 147-164.

ANDERSON, Elijah. (1999), Code of the Street: Decency, Violence, and the Moral Life of the Inner City. New York, W. W. Norton.

AUDARD, Catherine. (1993), Le Respect. De l'Estime à la Déférence: Une Question de Limite. Paris, Éditions Autrement.

BANFIELD, Edward C. (1992), Civility and Citizenship in Liberal Democratic Societies. New York, Paragon House.

BOUDON, Raymond. (1973), L'Inégalité des Chances. Paris, Armand Collin.

BOURDIEU, Pierre e PASSERON, Jean-Claude. (1964), Les Héritiers. Paris, Éditions de Minuit.

. (1970), La Reproduction. Paris, Éditions de Minuit.

BOURGOIS, Philippe. (1995), In Search of Respect. Selling Crack in El Barrio. Cambridge, Cambridge University Press.

CALDEIRA, Teresa P. R. (1984), A Política dos Outros. O Cotidiano dos Moradores da Periferia e o que Pensam do Poder e dos Poderosos. São Paulo, Editora Brasiliense.

CARVALHO, José Murilo de. (2001), Cidadania no Brasil. O Longo Caminho. Rio de Janeiro, Editora Civilização Brasileira. 
CHAUMONT, Jean-Michel e POURTOIS, Hervé (orgs.). (1999), "Souffrance Sociale et Attentes de Reconnaissance. Autour du Travail d'Axel Honneth". Recherches Sociologiques, vol. XXX, n을, Louvain.

DAMATTA, Roberto. (1979), Carnavais, Malandros e Heróis: Para uma Sociologia do Dilema Brasileiro. Rio de Janeiro, Editora Guanabara.

. (1985), A Casa e a Rua. Espaço, Cidadania, Mulher e Morte no Brasil. Rio de Janeiro, Editora Guanabara.

(1993), Conta de Mentiroso: Sete Ensaios de Antropologia Brasileira. Rio de Janeiro, Rocco.

DUCHESNE, Sophie. (1997), Citoyenneté à la Française. Paris, Presse de la Fondation Nationale des Sciences Politiques.

FONSECA, Claudia. (1984), “La Violence et la Rumeur: Le Code d'Honneur dans un Bidonville Brésilien". Revue Les Temps Modernes, no 455, pp. 2193-2235.

FRANKFURT, Harry. (1997), "Equality and Respect". Social Research, vol. 64, no 1, pp. 3-15.

GAUCHET, Marcel. (1980), “Tocqueville, l'Amérique et Nous. Sur la Genèse des Sociétés Démocratiques". Libre, 7, pp. 43-120.

HONNETH, Axel. (1995), The Struggle for Recognition. The Moral Grammar of Social Conflicts. Cambridge, MIT Press.

LECA, Jean. (1986), “Individualisme et Citoyenneté", in P. Birnbaum e J. Leca (eds.), Sur l'Individualisme. Paris, Presse de la Fondation Nationale des Sciences Politiques, pp. 159-209.

MARGALIT, Avishai. (1999), La Société Décente. Paris, Éditions Climats.

MARTUCCELLI, Danilo. (2002), Grammaires de l'Individu. Paris, Gallimard.

MERRIAN, Charles E. (1931), The Making of Citizens. Chicago, University of Chicago Press.

MILLER, William Ian. (1993), Humiliation: And Others Essays on Honor, Social Discomfort, and Violence. Ithaca/London, Cornell University Press.

PHARO, Patrick. (2001), La Logique du Respect. Paris, Les Éditions du Cerf.

RENAULT, Emmanuel. (2000), Mépris Social. Éthique et Politique de la Reconnaissance. Paris, Éditions du Passant.

REZENDE, Claudia Barcellos. (2001), “Entre Mundos. Sobre Amizade, Igualdade e Diferença”, in G. Velho e K. Kuschnir (orgs.), Mediação, Cultura e Política. Rio de Janeiro, Aeroplano Editora, pp. 237-264.

ROCHÉ, Sebastian. (1998), Sociologie Politique de l'Insécurité. Violences Urbaines, Inégalités et Globalisation. Paris, PUF.

ROSANVALLON, Pierre. (1992), Le Sacre du Citoyen. Histoire du Suffrage Universel en France. Paris, Gallimard.

SENNETT, Richard. (2003), Respect in a World of Inequality. New York, W. W. Norton.

SHKLAR, Judith. (1991), American Citizenship. Harvard, Harvard University Press. 


\section{Dominique Vidal}

SOUZA, Jessé. (2000), A Modernização Seletiva. Uma Reinterpretação do Dilema Brasileiro. Brasília, Editora UnB.

STEWART, Frank Henderson. (1994), Honor. Harvard, Harvard University Press.

TAYLOR, Charles. (1997), Multiculturalisme. Différence et Démocratie. Paris, Flammarion. . (1998), Les Sources du Moi. La Formation de l'Identité Moderne. Paris, Seuil.

THOMPSON, Dennis F. (1970), The Democratic Citizen. Social Science and Democratic Theory in the Twentieth Century. Cambridge, Cambridge University Press.

TODOROV, Tzvetan. (1995), La Vie Commune. Essai d'Anthropologie Générale. Paris, Seuil.

TÖNNIES, Ferdinand. (1977) [1887], Communauté et Société. Catégories Fondamentales de la Sociologie Pure. Paris, Retz-CEPL.

VAITSMAN, Jeni. (1997), “Pluralidade de Mulheres Urbanas de Baixa Renda”. Estudos Feministas, vol. 5, nํㅡㄹ, pp. 303-319.

VIDAL, Dominique. (1998), La Politique au Quartier. Rapports Sociaux et Citoyennetéà Recife. Paris, Éditions de la Maison de la Science de l'Homme.

_. (2000a), "Reflexões acerca da Contribuição da Experiência Brasileira para a Compreensão da Cidadania Democrática Brasileira". Contemporaneidade E Educação, ano $\mathrm{V}, \mathrm{n}$ 요 8, pp. 7-34.

. (2000b), "Vulnérabilité et Rapport à l'Espace. Être Pauvre et Citadin à Recife". Cahiers des Amériques Latines, n-35, pp. 91-108.

. (no prelo), “Entrer Pauvre dans la Vie Adulte à Recife”. Lusotopie.

WILSON, Peter. (1969), “Reputation and Respectability: A Suggestion for Caribbean Ethnology". Man, vol. 4, no 1, pp. 37-53. 


\section{ABSTRACT \\ The Language of Respect: The Brazilian Experience and the Meaning of Citizenship in Modern Democracies}

Based on field research in Recife and Rio de Janeiro, this article attempts to demonstrate why the analysis of the demand for respect, a central point in the social and political discourse of poor Brazilian city-dwellers, allows one to highlight a fundamental dimension in the meaning of democratic citizenship in modern societies. First, this demand indicates the importance of the attachment to respect and the denouncement of humiliation among low-income urban Brazilians. Second, it unveils the tension between hierarchy and equality. The article then goes on to evoke certain social and political representations among the populations studied, leading to questions about the relationship between moral life and the right to legal protection. Finally, the article discusses how the importance ascribed to morality is relevant to contemporary discussion on the sociology of recognition.

Key words: citizenship; democracy; respect

\section{RÉSUMÉ}

Le Langage du Respect. L'Expérience Brésilienne et le Sens de la Citoyenneté dans les Démocraties Modernes

A partir d'enquêtes de terrain à Recife et à Rio de Janeiro, dans cet article on se propose de montrer en quoi l'analyse de la demande de respect, centrale dans le discours social et politique des pauvres urbains brésiliens, permet de mettre en évidence une dimension centrale du sens de la citoyenneté démocratique dans les sociétés modernes. On souligne d'abord la centralité de l'attachement au respect et de la dénonciation de l'humiliation dans les milieux populaires urbains brésiliens. O s'intéresse ensuite à la tension entre hiérarchie et égalité que ce souci de respect exprime. Puis, on évoque certaines des représentions sociales et politiques des populations considérées, ce qui nous amène à interroger le rapport entre vie morale et droit à la protection juridique. On verra, enfin, comment l'importance accordée à la moralité présente un intérêt pour les discussions contemporaines en sociologie de la reconnaissance.

Mot-clés: citoyenneté; démocraties; respect 